\title{
Physicochemical, Cooking and Textural Properties of Different Genotypes of Paddy
}

\author{
Praveen Kumar Patle*, S. S. Shukla, Ankit Bharti and G. K. Rana \\ Department of Food Science and Technology, Jawaharlal Nehru Krishi Vishwa Vidhyalaya \\ Jabalpur (MP)- 482004, India \\ *Corresponding author
}

\begin{tabular}{l} 
K e y w o r d s \\
Genotype, \\
Geometric means \\
diameter, Aspect \\
ratio, Porosity, \\
Milling and Hulling \\
\hline Article Info \\
Accepted: \\
07 March 2020 \\
Available Online: \\
10 April 2020
\end{tabular}

\section{A B S T R A C T}

\section{Introduction}

Rice (Oryza sativa L.) is the most important and extensively grown food crop in the world and the staple food of more than 60 percent of the world population. Rice is primarily a high calorie food. The major part of rice consists of carbohydrate in the form of starch, which is about 72- 75 percent of the total grain composition and the protein content of rice is around 7 percent. The rice production, processing and marketing constitute the biggest industry in the country expanded rice and popped rice (Sulochana et al., 2007). In the last couple of years several high yielding varieties have been evolved by plant breeders.

Milling is an important unit operation in processing of rice, accuracy, and efficiency of milling machine along with grains behavior 
during milling largely determine the market value of grain. The main aim of milling is to get edible, white rice kernel that is sufficiently milled and free of impurities (Singh et al., 2015). The byproducts of milling are husk, germ, bran layers, and broken rice. The most important parameter of rice processing is the percentage of whole or head rice. To the best of our knowledge, there is no literature available regarding the characterization of rice genotypes.

The cooking qualities of rice is key factor for their economic values, which can be measured in terms of cooking time, grain elongation during cooking, and length breadth ratio after cooking. Cooking quality depends upon the physical and chemical characteristics of starch, such as amylose-amylopectin ratio, gel consistency, and gelatinization temperature (Tan, Li, Yu, Xing, and $\mathrm{Xu}$, 1999). Amylose content is one of the important characteristics influencing the cooking behavior (Xie, et al., 2007).

Rice variety with more than $25 \%$ of amylose content absorbs more water and has a fluffy texture after cooking (Frei, et al, 2003). Linear elongation of rice upon cooking is considered one of the major characteristics of good rice. Rice which expands only along length without increase in girth is considered high-quality rice (Sood and Sadiq, 1979). Gelatinization temperature has a direct relationship with grain elongation during cooking. Perez, et al., (1987) reported that rice with high gelatinization temperature elongates less during cooking.

\section{Materials and Methods}

\section{Experimental site, geographical situation and climatic condition}

The experiment was conducted in the Grain Science and Crop Quality Laboratory of
Department of Food Science and Technology, JNKVV Jabalpur (MP) and Shree Sharda Balaghat (MP).

\section{Materials}

The sample $500 \mathrm{gm}$ each of 10 genotypes of paddy was procured from Breeder Seed Production Unit, Department of Plant Breeding and Genetics, JNKVV Jabalpur (MP).

The genotype shown in table 1 was used in the study. The sample materials were properly cleaned, graded and then properly packed in cloth bags and stored at ambient condition for further use in experiments.

\section{Method}

Physical properties of different genotypes of paddy- Testweight-1000 grain weighed of different genotypes of paddy was determined by counting grains and recording their weight using digital weighing balance with an accuracy of $0.001 \mathrm{~g}$. The average value of 3 replications was recorded. Dimensions (length, width and thickness)-100 grains were randomly selected and their three principle dimensions (length, width and thickness) were measured using a Venire caliper to an accuracy of $0.01 \mathrm{~cm}$. length (L) is defined as the distance from the tip cap to the kernel crown, width (W) is defined as the widest point to point measurement taken parallel to the face of the kernel, thickness (T) is defined as the distance between the two kernel faces. Bulk density-Bulk density is the ratio of sample weight to its total volume; it was determined by filling a $100 \mathrm{ml}$ graduated cylinder with known quantity of sample.

The cylinder was gradually tapped few times and recorded for its volume (Mohsenin, 1970). True density-True density was determined by adding $10 \mathrm{~g}$ of paddy grains in 
$20 \mathrm{ml}$ toluene in $100 \mathrm{ml}$ measuring cylinder. The final volume was noted and true volume of paddy sample was determined from the difference. The true density of the sample was expressed as the ratio of weight of sample and the true volume, $\mathrm{g} / \mathrm{ml}^{3}$ (Mohsenin, 1970). Angle of repose $(\theta)$-The angle of repose for the grain was determined by the method suggested by Waziri and Mettal (1983). The grains were heaped over a circular disc of 200 $\mathrm{mm}$ diameter by allowing them to fall from a height of $300 \mathrm{~mm}$ until maximum height was reached. The height was replicated ten times and readings were recorded. Milling characteristics of different genotypes of paddy-The weights were used to determine the Hulling and Milling characteristics, Head Rice Recovery Percentage (HRR) and Broken Rice Percentage (BRP) as described by Ghosh et al (1971). Milling and Broken PercentageWeight of polished rice includes head and broken also. The milling and broken percentage (MP) is calculated by the following formula suggested by Ghosh et al., (1971).

\section{Cooking properties}

Cooking time and Elongation ratio (Er)-For cooking quality, both pressure and microwave cooking were used Cooking properties determined by Dipti, et al., (2002) Cooked rice length/breadth ratio $(\mathrm{Clb})$-The length/breadth ratio was determined by dividing the cumulative length to breadth ratio of cooked rice.

\section{Statistical analysis}

The data was subjected to one-way analysis of variance (ANOVA) at 5\% level of significance. The skeleton of ANOVA for complete randomized design (CRD) is presented in table given below: (Cyprien and Kumar, 2012).

\section{Results and Discussion}

The study was planned to evaluate the milling characteristics of new genotypes of paddy (Oriza sativa L.) and their utilization for cooking rice. Various physical properties of paddy and cooked rice viz. length, breadth, test weight, bulk density, true density, angle of repose, hulling, milling percentage, total head rice recovery and broken percentage of rice were considered as chief criteria of determination. The evaluation of milling and cooking quality of rice was conducted to evaluate genotypital variation in quality attributes. The findings obtained during the course of investigation are presented asunder.

\section{Physical properties of different genotypes of paddy}

\section{Length, breadth and test weight of paddy genotypes}

The result of seed length and seed breadth of 10 genotypes of paddy are given in the Table 1 Perusal of the data indicated that mean values of ranged from 8.77 to $9.88 \mathrm{~mm}$. the genotype NPT-29 showed the highest length, breath and test weight, whereas NPT-65 had the lowest. On statistical analysis, it becomes evident that genotype NPT-29 with the highest dimension was significantly superior over the other genotypes.

A perusal of (Table 1) indicates that mean values of length, breath and test weight ranged from 8.77 to $9.88,2.01$ to $3.09 \mathrm{~mm}$ and 30.19 to $27.06 \mathrm{~mm}$. The statistical analysis indicated a significant variation in the length, breadth and test weight of paddy genotypes.

The present findings are in conformity with the reports of Ghasemi et al., (2007), Varnamkhasti et al., (2009), Ashtiani et al., (2010) and Zareiforoush et al., (2011). 
Bulk density, true density and angle of repose of paddy genotypes

The bulk density of 10 paddy genotypes is given in the Table 2 the data indicated that mean values of bulk density varied from 0.59 to $0.68\left(\mathrm{gm} / \mathrm{ml}^{3}\right)$.The genotypes JRH-107 was recorded maximum Bulk density, while NPT81-01 exhibited lowest. The genotype JRH107 found to significantly superior; however, all other genotypes were non -significant for bulk density parameter.

The true density of the Table 1 the data indicated that mean values of true density ranges from 1.12 to $1.44\left(\mathrm{gm} / \mathrm{ml}^{3}\right) \mathrm{JRH}-102$ genotypes was recorded with maximum true density while JRH-5 exhibited lowest true density. The genotype JRB-1, NPT-13-01, NPT-29, NPT-65 and NPT-88 were found to be significantly superior over rest of the cultivars for mean value true density.

Table 1 comprises the results of angle of repose of 10 genotypes of paddy. The mean values of angle of repose varied from 29.37 to 32.45. The maximum was recorded in JRB-1 and minimum in NPT-65. No significant difference exists among the genotypes for angle of repose parameter.

The results show significant difference among the genotypes for above parameters. The present findings can be substantiated with the reported values of Ashtiani et al., (2010) and Varnamkhasti et al., (2009).

\section{Milling characteristics of different genotypes of paddy}

\section{Hulling, milling and head rice recovery percentage}

The hulling and milling percentage of 10 genotypes are shown in Table 2 An appraisal of the table indicates that hulling percentage was found minimum in JRB-1 (77.05\%) and maximum in NPT 81-01 (82.18\%). Paddy line NPT-29 was significantly superior over all other paddy genotypes.

The milling percentage 2 was found to be varied from 65.05 to 67.53 percent. The minimum milling percentage was recorded in genotype JRB-1. Whereas it was maximum in JRH -19 cultivar. A significant difference was found to exist among the genotypes for milling percentage parameter.

Table 2 depicts the results of head rice recovery after milling of various cultivars of paddy. It was found to be lowest in genotypes JRB-1 (48.89\%) and highest in JRH-5 $(58.66 \%)$. The findings suggest that JRH-5 line was significantly superior over all other lines to provide highest head rice recovery. A significant difference among the lines was found to exist as regards for head rice recovery parameter. The present findings of milling characteristics are in conformity with the reported results of Pan et al., (2007), Shigang (2006) and Verma et al., (2014).

\section{Cooking qualities of different genotypes of paddy}

\section{Kernel L/B ratio before cooking and after cooking}

Table 3 indicates the results of kernel 1/b ratio before cooking. It varies from $\mathrm{mm}$ and 2.08 to $2.53 \mathrm{~mm}$. The paddy cultivar JRH -107 was recorded with maximum $\mathrm{L} / \mathrm{B}$ ratio and while genotypes NPT13-01 recorded minimum L/B ratio before cooking. A significant difference among the genotypes was found to exist as regards for Kernel length and breadth ratio before cooking parameter.

Table 3 presents the results of kernel L/B ratio after cooking. It varies from 2.47 to 3.05 $\mathrm{mm}$. The paddy cultivar JRH-107 was recorded with maximum kernel $\mathrm{L} / \mathrm{B}$ ratio while genotype NPT-65 recorded minimum 
kernel L/B ratio after cooking. The present findings of cooking characteristics are in conformity with the reported results of Yadav et al., (2007) and Ramkumar et al., (2010).

\section{Elongation ratio and cooking time}

The elongation ratio 3 was found to be varied from 1.32 to 1.44 percent. The minimum elongation ratio was recorded in genotype
JRH-19. While it was maximum in JRH -107 cultivar. A significant difference was found to exist among the genotypes for elongation ratio.

Cooking time was found to be range from 23.95 to 25.83 minute. The minimum cooking time taken JRH-19 paddy genotype and the maximum time require was NPT 81-01 in genotypes of paddy.

Table.1 Physical property (Length, Breadth and Test weight) of different varieties of paddy

\begin{tabular}{|l|l|l|l|l|c|c|c|}
\hline S.No. & Varieties & $\begin{array}{l}\text { Length } \\
(\mathbf{m m})\end{array}$ & $\begin{array}{l}\text { Breadth } \\
(\mathbf{m m})\end{array}$ & Test weight $\mathbf{( g )}$ & $\begin{array}{l}\text { Bulkdensity } \\
\text { gm/ml }^{\mathbf{3}}\end{array}$ & $\begin{array}{c}\text { True } \\
\text { densitygm/ml }\end{array}$ & $\begin{array}{l}\text { Angle of } \\
\text { repose }^{\mathbf{3}}\end{array}$ \\
\hline $\mathbf{1 .}$ & JRB-1 & 9.90 & 2.02 & 27.12 & 0.64 & 1.37 & $\mathbf{3 2 . 4 5}$ \\
\hline $\mathbf{2 .}$ & JRH-107 & 9.64 & 2.68 & 28.76 & 0.68 & 1.16 & $\mathbf{3 0 . 9 8}$ \\
\hline $\mathbf{3 .}$ & JRH-19 & 9.37 & 2.13 & 28.65 & 0.65 & 1.19 & $\mathbf{2 9 . 8 7}$ \\
\hline $\mathbf{4 .}$ & JRH-5 & 9.02 & 2.16 & 29.14 & 0.60 & 1.12 & $\mathbf{3 0 . 6 5}$ \\
\hline $\mathbf{5 .}$ & JRH-102 & 9.66 & 2.60 & 28.94 & 0.62 & 1.44 & $\mathbf{3 0 . 1 6}$ \\
\hline $\mathbf{6 .}$ & NPT13-01 & 9.89 & 2.45 & 30.11 & 0.63 & 1.43 & $\mathbf{3 0 . 3 2}$ \\
\hline $\mathbf{7 .}$ & NPT81-01 & 8.50 & 2.80 & 29.43 & 0.59 & 1.41 & $\mathbf{3 0 . 1 1}$ \\
\hline $\mathbf{8 .}$ & NPT-29 & 9.88 & 3.09 & 28.88 & 0.65 & 1.40 & $\mathbf{2 9 . 9 5}$ \\
\hline $\mathbf{9 .}$ & NPT-88 & 9.12 & 2.36 & 29.48 & 0.66 & 1.38 & $\mathbf{3 0 . 1 7}$ \\
\hline $\mathbf{1 0 .}$ & NPT-65 & 8.77 & 2.05 & 27.96 & 0.64 & 1.44 & $\mathbf{2 9 . 3 7}$ \\
\hline & C.D.@5\% & $\mathbf{0 . 2 4}$ & $\mathbf{0 . 2 5}$ & $\mathbf{0 . 0 8}$ & $\mathbf{0 . 0 8}$ & $\mathbf{0 . 2 6}$ & $\mathbf{3 . 3 0}$ \\
\hline
\end{tabular}

Table.2 Milling characteristics of different varieties of paddy

\begin{tabular}{|c|c|c|c|c|}
\hline S. No. & Varieties & Hulling $(\mathbf{\%})$ & Millig(\%) & Head rice recovery $(\mathbf{\%})$ \\
\hline $\mathbf{1 .}$ & JRB-1 & 77.05 & 65.05 & $\mathbf{4 8 . 8 9}$ \\
\hline $\mathbf{2 .}$ & JRH-107 & 79.17 & 66.64 & $\mathbf{5 3 . 8 3}$ \\
\hline $\mathbf{3 .}$ & JRH-19 & 80.5 & 67.31 & $\mathbf{5 6 . 5 5}$ \\
\hline $\mathbf{4 .}$ & JRH-5 & 82.01 & 67.53 & $\mathbf{5 6 . 6 6}$ \\
\hline $\mathbf{5 .}$ & JRH-102 & 81.12 & 67.13 & $\mathbf{5 5 . 1 4}$ \\
\hline $\mathbf{6 .}$ & NPT13-01 & 82.18 & 67.45 & $\mathbf{5 4 . 6 0}$ \\
\hline $\mathbf{7 .}$ & NPT81-01 & 81.09 & 66.60 & $\mathbf{5 4 . 7 5}$ \\
\hline $\mathbf{8 .}$ & NPT-29 & 84.07 & 67.48 & $\mathbf{5 5 . 4 3}$ \\
\hline $\mathbf{9 .}$ & NPT-88 & 83.36 & 65.59 & $\mathbf{5 4 . 2 4}$ \\
\hline $\mathbf{1 0 .}$ & NPT-65 & 81.28 & 67.21 & $\mathbf{5 3 . 8 6}$ \\
\hline & C.D. @ 5 $\%$ & $\mathbf{0 . 1 5}$ & $\mathbf{0 . 0 8}$ & $\mathbf{0 . 2 3}$ \\
\hline & SE(m) \pm & $\mathbf{0 . 0 5}$ & $\mathbf{0 . 0 3}$ & $\mathbf{0 . 0 8}$ \\
\hline
\end{tabular}


Table.3 Physical properties of different genotypes of rice before cooking and after cooking

\begin{tabular}{|l|l|c|c|c|c|}
\hline S. No. & Varieties & $\begin{array}{c}\text { L/B ratio } \\
\text { BC(mm) }\end{array}$ & $\begin{array}{c}\text { L/B } \\
\text { AC(mm) }\end{array}$ & Elongation Ratio & $\begin{array}{c}\text { Cooking } \\
\text { time (mint.) }\end{array}$ \\
\hline $\mathbf{1 .}$ & JRB-1 & 2.20 & 2.97 & 1.36 & $\mathbf{2 4 . 1 1}$ \\
\hline $\mathbf{2 .}$ & JRH-107 & 2.53 & 3.05 & 1.44 & $\mathbf{2 3 . 9 5}$ \\
\hline $\mathbf{3 .}$ & JRH-19 & 2.32 & 2.93 & 1.32 & $\mathbf{2 3 . 6 6}$ \\
\hline $\mathbf{4 .}$ & JRH-5 & 2.30 & 3.02 & 1.35 & $\mathbf{2 4 . 1 7}$ \\
\hline $\mathbf{5 .}$ & JRH-102 & 2.31 & 3.01 & 1.36 & $\mathbf{2 5 . 7 9}$ \\
\hline $\mathbf{6 .}$ & NPT13-01 & 2.08 & 3.27 & 1.37 & $\mathbf{2 5 . 8 3}$ \\
\hline $\mathbf{7 .}$ & NPT81-01 & 2.16 & 2.90 & 1.42 & $\mathbf{2 4 . 6 6}$ \\
\hline $\mathbf{8 .}$ & NPT-29 & 2.12 & 2.53 & 1.40 & $\mathbf{2 3 . 9 7}$ \\
\hline $\mathbf{9 .}$ & NPT-88 & 2.19 & 2.47 & 1.35 & $\mathbf{2 5 . 1 2}$ \\
\hline $\mathbf{1 0 .}$ & NPT-65 & 2.18 & 2.47 & 1.38 & $\mathbf{2 4 . 0 8}$ \\
\hline & C.D.@5\% & $\mathbf{0 . 0 8}$ & $\mathbf{0 . 3 4}$ & $\mathbf{0 . 1 3}$ & $\mathbf{2 . 6 8 3}$ \\
\hline & SE(m) \pm & $\mathbf{0 . 0 3}$ & $\mathbf{0 . 1 2}$ & $\mathbf{0 . 0 5}$ & $\mathbf{0 . 8 6 1}$ \\
\hline
\end{tabular}

$* \mathrm{~L} / \mathrm{B}$ ratio $\mathrm{BC}$ - length / width ratio after cooking; $* \mathrm{~L} / \mathrm{B}$ ratio AC- length / width ratio after cooking

The varietal differences showed significant $(p<0.05)$ effect on elongation ratio and it ranged from 1.36 to 1.64. Dan-baba et al., (2011) reported that cooked length to breadth ratio and amylose content incenses the elongation ratio of rice.

In conclusion the ten rice genotypes were evaluated for physical, cooking and milling characteristics. The ten genotypes included JRH-107 the highest bulk density compared to other nine genotypes. Thousand kernel weight was observed to be highest forNPT-29 and lowest for JRH-1. All genotypes showed similar shape characteristic as $1 / b$ ratio did not differ significantly between the genotypes. Milling behavior of all the ten genotypes was same. The broken rice percentage and head rice yield did not differ significantly between the genotypes It was observed that all the genotypes had intermediate quality in term of head rice yield. Cooking characteristic did not differ significantly between the genotypes. The rice genotypes took $23.66-25.83 \mathrm{~min}$ to cook. JRH-107genotypes increased in length after cooking, the increase in length after cooking is a desirable trait of rice and is mark of high-quality rice.

\section{References}

Ashatinie AH, Sadeghi M. and Hemmat A. (2010). Some physical properties of two rough rice varieties as affected by moisture content. 24: 205 - 20.

Cyprien M. and Kumar V. (2012). A comparative statistical analysis of rice cultivars data. Journalof Reliability and Statistical Studies. 5(2):143-161.

Danbaba N., Anounye, J. C., Gana, A. S., Abo, M. E., and Ukwungwu, M. N. (2011). Grain quality characteristics of ofada rice (oryza sativa 1.): cooking and eating quality. International Food Research Journal, 18 (2), 629-634.

Dipti, S. S., Hossain, S. T., Bari, M. N., and Kabir, K. A. (2002). Physicochemical and cooking properties of some fine rice varieties. Pakistan Journal of Nutrition, 1, 188-190.

Frei, M., Siddhuraju, P., and Becker, K. (2003). Studies on the in vitro starch digestibility and the glycemic index of six different indigenous rice cultivars from the Philippines. Food Chemistry, 83,395402.10.1016/S0308-8146(03)00101-8 
Ghasemi VM, Mobli H, Jafari A, Rafiee, S, Soltanabadi M, and Kheiralipour K. (2007). Some engineering properties of paddy (Var. Sazandegi). International Journal of Agriculture and Biology. 5: 763 - 766.

Ghosh AK, Nanda B B, Swami SG and Nayak BB. (1971). Influence of nitrogen on the physico- chemical characteristics of rice grain. Oryza. 891: 87-97.

Mohsenin, N.N., (1970). Physical Properties of Plant and Animal Materials. 1st Edn.,Gordon and Breach Science Publishers, New York,USA.

Pan, Z., Ragab, K., Larry, G., Richard, L., Jams, J.T. and Adel, S. (2008a). Feasibility of simultaneous rough rice drying and disinfestations by infrared radiation heating and rice milling quality. J. Food Eng. 48, 469-479.

Perez, C. M., Juliano, B. O., Pascual, C. G., and Novenario, V. G. (1987). Extracted lipids and carbohydrates during washing and boiling of milled rice. Starch-Stärke, 39, 386-390.10.1002/star.19870391105

Ramkumar G, Sivaranjani AKP, MamishK, Panday, Sakthivel K. (2010). Development of a PCR based SNP marker system for effective selection of kernel length and kernel elongation in rice. Mol. Breeding. 26:735-740.

Shi-gang, B. (2006). Study on the relationship between the moisture content of brown rice and milling characteristics. J. Northeast Agric. Univ., China,

Statistics Agriculture at a Glance, (2016). http://eands.dacnet.nic.in/PDF/Glance2016.pdf

Singh R. (1999). Studies on milling characteristics of some prominent varieties of paddy grown in Chhattisgarh region. Un-published $M$. tech thesis, IGKV, Raipur (C.G.).

Sulochana S, Singaravadivel K, Vidyalakshmi R and Dakshinamurthy A. 2007. A profile of the flaked rice industry in India. Cereal Food World. 52(5): 257- 261.Tan, Y. F., Li, J. X., Yu, S. B., Xing, Y. Z., and Xu, C. G. (1999). The three important traits for

cooking and eating quality of rice grains are controlled by a single locus in an elite rice hybrid, Shanyou 63.

Sood, G. B., and Sadiq, E. A. (1979). Geographical distribution of kernel elongation gene(s) in rice. Indian Journal of Genetics and Plant Breeding, 40, 439-342.

Varnamkhasti MG, Mobli H, Jafari A, Keyhani AR, Soltanabadi MH, Rafiee, $\mathrm{S}$ and Kheiralipour

K. (2008). Some physical properties of rough rice (oryza sativa 1.) grain. Journal of Cereal Science, 47(3):496-501.

Verma DK, Mohan M, Prabhakar PK and Srivastav PP. (2014). Physicochemical and cooking characteristics of Azad basmati. International Food Research Journal 22(4): 1380- 1389.

Waziri AN. and Mittal JP. (1983). Design related physical properties of selected agricultural products. Agricultural Mechanization in Asia, Africa and Latin America, 14: 59- 62

Yadav BS, Yadav RB and Khatkar BS. (2007). Morphological, physicochemical and cooking properties of some Indian rice (Oryza sativa L.) cultivars. Journal of Agricultural Technology, 3(2): 203-210.

Xie, L., Chen, N., Duan, B., Zhu, Z., and Liao, X. (2007). Impact of proteins on pasting and cooking properties of waxy and non-waxy rice. Journal of Cereal Science, 47, 372379.

Zareiforoush H, Osseinzadeh BH, Adabi ME and Motavali A. (2011). Moisture dependent physical properties of paddy grains. Journal of American Science, 7(7).

\section{How to cite this article:}

Praveen Kumar Patle, S. S. Shukla, Ankit Bharti and Rana, G. K. 2020. Physicochemical, Cooking and Textural Properties of Different Genotypes of Paddy. Int.J.Curr.Microbiol.App.Sci. 9(04): 552-558. doi: https://doi.org/10.20546/ijcmas.2020.904.067 